\title{
Comparison of Total and Salivary Cortisol in a Low-Dose ACTH (Synacthen) Test: Influence of Three-Month Oral Contraceptives Administration to Healthy Women
}

\author{
K. ŠIMŮNKOVÁ, L. STÁRKA, M. HILL, L. Ǩ̌ÍŽ, R. HAMPL, K. VONDRA \\ Institute of Endocrinology, Prague, Czech Republic
}

Received November 12, 2007

Accepted January 28, 2008

On-line February 13, 2008

\section{Summary}

The objective of this study was to evaluate the influence of lowdose combined oral contraception (COC) on basal and stimulated (1 $\mu \mathrm{g} \mathrm{ACTH} \mathrm{test)} \mathrm{levels} \mathrm{of} \mathrm{serum} \mathrm{and} \mathrm{salivary} \mathrm{cortisol} \mathrm{(F),}$ cortisone and on basal serum cortisol binding globulin (CBG), adrenocorticotropic hormone (ACTH), dehydroepiadrosterone (DHEA) and calculated free cortisol in healthy young women. Three-month administration of $\mathrm{COC}$ resulted in 1) significant increase of basal $(454.0 \pm 125.0$ to $860.9 \pm 179.7 \mathrm{nmol} / \mathrm{l})$ and ACTH-stimulated serum cortisol in $30^{\text {th }}$ min $(652.3 \pm 60.5$ to $1374.1 \pm 240.6 \mathrm{nmol} / \mathrm{l})$; 2) no significant change of basal (15.4 \pm 7.3 to $18.9 \pm 8.5 \mathrm{nmol} / \mathrm{l})$ and $\mathrm{ACTH}$-stimulated salivary cortisol at the $30^{\text {th }} \min (32.4 \pm 8.8$ to $\left.32.9 \pm 9.0 \mathrm{nmol} / \mathrm{l}) ; 3\right)$ no significant change of basal serum cortisone $(38,8 \pm 7.68$ to $45.2 \pm 24.2 \mathrm{nmol} / \mathrm{l})$ and $\mathrm{ACTH}$-stimulated cortisone at the $30^{\text {th }}$ (34.8 \pm 10.9 to $47.0 \pm 35.7 \mathrm{nmol} / \mathrm{l}) ; 4$ ) significant increase of basal ACTH $(17.2 \pm 9.0$ to $38.2 \pm 29.4 \mathrm{ng} / \mathrm{l}), \mathrm{CBG}(991.0 \pm 161.0$ to $2332.0 \pm 428.0 \mathrm{nmol} / \mathrm{l}$ ), and 5) no significant change of basal DHEA $(24.6 \pm 15.7$ to $22.6 \pm 11.7 \mu \mathrm{mol} / \mathrm{l})$ and calculated basal value for free cortisol $(22.8 \pm 14.9$ to $19.2 \pm 6.9 \mathrm{nmol} / \mathrm{l})$. In conclusions, higher basal and ACTH-stimulated serum cortisol were found after three-month administration of $\mathrm{COC}$, while basal and stimulated salivary cortisol were not significantly affected. Therefore, salivary cortisol can be used for assessment of adrenal function in women regularly using COC.

\section{Key words}

Low dose ACTH test • Salivary cortisol - Total serum cortisol • Free cortisol • Cortisol binding globulin • Oral contraceptives

\section{Corresponding author}

K. Šimůnková, Institute of Endocrinology, Národní třída 8, 11694

Prague 1, Czech Republic. E-mail: ksimunkova@endo.cz

\section{Introduction}

Most of the cortisol (F) present in circulation is bound to proteins; only a small portion is found as free hormone, exerting hormonal activity. It is known that certain clinical conditions and drugs, for example estrogens as the component of hormonal contraception (COC), affect plasma concentration of cortisol binding globulin (CBG) and alter the total cortisol concentration. By contrast, the unbound fraction of cortisol is independent of $\mathrm{CBG}$ changes. Therefore, interpretation of the results of hypothalamic-pituitary-adrenal (HPA) axis based merely on the total serum cortisol level can be misleading (ChristCrain et al. 2007, Gozansky et al. 2005).

As determination of free cortisol level in serum is not carried out routinely due to methodical reasons, alternative methods for adrenal function assessment were sought. One such possibility is to calculate the free cortisol index, a second is to determine salivary cortisol. Methodological details of salivary cortisol estimation have been published in recent papers (Šimůnková et al. 2007, Marcus-Perlman et al. 2006, Christ-Crain et al. 2007, Ho et al 2006.). The salivary cortisol measurement reflecting the free hormone fraction in serum appeared to be advantageous, which has been confirmed and successfully employed in diagnostics of HPA axis disorders (Gozansky et al. 2005, Contreras et al. 2004, Marcus-Perlman et al. 2006). This approach was frequently used as a screening test for the diagnosis of Cushing's syndrome as well (Bjorntorp and Rosmond 1999, Reynolds et al. 2001, Vicennati and Pasquali 2000, Aardal and Holm 1995). Further advantages of salivary cortisol examination are non-invasive sample collection and its applicability in non- 
standard conditions in outpatient clinics (Aardal and Holm 1995, Contreras et al. 2004).

Women using COC represent a large population group, including patients with autoimmune disorders and diabetes mellitus type I. The latter groups should have adrenal function examined regularly because of the higher risk of adrenal autoimmune function disturbances (Barker 2006, Betterle et al. 2002). In emergency situations and some other circumstances, it is necessary to test adrenal gland function as soon as possible without waiting for withdrawal of $\mathrm{COC}$ and consequent serum $\mathrm{CBG}$ and $\mathrm{F}$ correction influenced by $\mathrm{COC}$ use. For assessment of the adrenal reserve, a physiological stimulation has been used, which is ensured by administration of $1 \mu \mathrm{g}$ ACTH-low dose Synacthen test (Dickstein et al. 1991).

Therefore, we decided to obtain more detailed data on the influence of low-dose hormonal contraception (COC) on the basal and stimulated (1 $\mu \mathrm{g}$ ACTH test) levels of serum and salivary cortisol (F) and serum cortisone in healthy young women. In addition to serum and salivary cortisol, basal serum $\mathrm{CBG}$, adrenocorticotropic hormone (ACTH), calculated free serum F, serum cortisone and DHEA were measured in order to detect possible changes in the HPA axis and peripheral tissue metabolism of glucocorticoids.

\section{Subjects and Methods}

\section{Subjects}

Eleven healthy, 22-30 year-old women with normal weight (BMI within $20-25 \mathrm{~kg} / \mathrm{m}^{2}$ ) were examined in the follicular phase of the menstrual cycle without using hormonal contraceptives (baseline period). None of them used any other medication affecting adrenal function for at least three months before testing. The same women were investigated after three-month administration of oral contraceptives (COC period). The contraceptives used by these subjects were monophasic, with either $30 \mu \mathrm{g}$ ethinylestradiol $+2 \mathrm{mg}$ dienogestodum, $20 \mu \mathrm{g}$ ethinylestradiol $+75 \mu \mathrm{g}$ gestodenum, or $35 \mu \mathrm{g}$ ethinylestradiol $+250 \mu \mathrm{g}$ norgestimatum. The protocol of the study was approved by the Ethical Committee of the Institute of Endocrinology, and the subject signed the informed consent.

\section{The low-dose (1 $\mu \mathrm{g})$ ACTH (Synacthen) test}

The tests were carried out in the Institute of Endocrinology, Prague, in the Laboratory for Function Tests, always starting at 9.00 a.m., after an overnight fast.
Sixty minutes before the test the subjects were not allowed to smoke, drink liquids or brush their teeth. After a 30-min rest in bed with a cannula introduced into the cubital vein, samples of blood and saliva were taken, and then $1 \mu \mathrm{g}$ of ACTH was administered intravenously (Time 0 ). The samples of blood and saliva were taken at the $20^{\text {th }}$ $30^{\text {th }}, 40^{\text {th }}$ and $60^{\text {th }}$ minutes after ACTH administration, while patients were in a supine position. Basal concentration of $\mathrm{ACTH}, \mathrm{CBG}$, calculated value of free cortisol, DHEA were measured, basal and ACTHstimulated serum, salivary cortisol and serum cortisone were measured. Thirty minutes after sample collection, blood was centrifuged at $3000 \mathrm{rpm}$ for $15 \mathrm{~min}$. and serum was collected into plastic tubes. Saliva was sampled by spitting into plastic tubes; both serum and saliva samples were frozen at $-20{ }^{\circ} \mathrm{C}$ and stored at this temperature until analysis. No saliva sample was contaminated with blood. The above-described low-dose ACTH test was performed twice in every woman, at the baseline period and after 3 months use of COC (COC period).

\section{Solution preparation}

The entire content of an ampoule with ACTH (250 $\mu \mathrm{g} / \mathrm{ml}$ ) (Synacthen, Novartis Pharma $\mathrm{GmbH}$, Nurnberg, Germany) was added to $249 \mathrm{ml}$ of sterile 0.9 $\% \mathrm{NaCl}$ (saline) solution. One milliliter of this solution was administered intravenously during ACTH test, corresponding to $1 \mu \mathrm{g}$ of ACTH. The dose was prepared at most $10 \mathrm{~min}$ before administration.

A high performance liquid chromatography (HPLC) system (Dionex Softron, Germering, Germany) was used for separation of cortisol from cortisone and for their quantification. It consisted of a HPLC pump system P 680 equipped with automatic flow rate control, automated sample injector ASI-100, thermostated column compartment TCC-100 and photodiode array detector PDA-100 with wavelength range 190-600 nm. A speedvacuum centrifuge (HETO, Melsungen, Germany) was used for solvent evaporation.

Serum cortisol and cortisone concentrations were determined by a method using high HPLC with UV/VIS detection.

Serum sample $(200 \mu \mathrm{l})$ was diluted with releasing buffer $(200 \mu \mathrm{l})$ and 4-androsten-3, 17-dione$11 \beta$-ol (40 ng per sample) was added as an internal standard. Buffered sample solution was extracted with diethylether $(2 \mathrm{ml})$ for $1 \mathrm{~min}(2000 \mathrm{rpm})$ and frozen. The organic phase containing released steroids was decanted and evaporated under the stream of nitrogen. 
To avoid possible column contamination from free fatty acids, the dry residue from the extract was dissolved in $80 \%$ methanol $(1 \mathrm{ml}, \mathrm{v} / \mathrm{v})$ and $\mathrm{n}$-hexane (1 $\mathrm{ml})$. The mixture was extracted again for $1 \mathrm{~min}$ (2000 rpm). N-hexane-containing phase was removed and discarded. The residual polar phase was evaporated at $55{ }^{\circ} \mathrm{C}$ and the dry residue was dissolved in $15 \%$ acetonitrile $(50 \mu \mathrm{l}, \mathrm{v} / \mathrm{v})$ and mixed vigorously to rinse the tube walls appropriately. The samples were then centrifuged (2000 $\left.\mathrm{g}, 3 \mathrm{~min}, 22^{\circ} \mathrm{C}\right)$ and decanted solution transferred into vials.

Simultaneously, blank samples and quality control samples were processed in the same way to avoid possible contamination and to determine procedural losses of individual metabolites.

\section{HPLC separation}

Standard mixtures of cortisone and cortisol in the following concentrations were used for calibration by an external standard method: cortisone $(25,50,100,250$, 500, 625 and $750 \mathrm{pg} / \mu \mathrm{l})$, cortisol (100, 250, 500, 750, $1500,2250$ and $3000 \mathrm{pg} / \mu \mathrm{l})$. HPLC separation was carried out with reverse phase Macherey-Nagel EC 250/4 nucleosil 100-5 $\mathrm{C}_{18}$ column $(250 \mathrm{x} 4 \mathrm{~mm})$ with particle size of $5 \mu \mathrm{m}$ (Macherey-Nagel, Dueren, Germany). The following protocol was used.

Elution gradient: $0.0-2.1 \mathrm{~min}$ constant mobile phase acetonitrile-water (15:85), 2.1-12.0 min, linear gradient from methanol-acetonitrile-water (40:9:51) to methanol-acetonitrile-water $\quad(49: 11.3: 39.7), \quad 12.0-15.0$ min, constant mobile phase methanol (100\%), 15.0-19.0, constant mobile phase acetonitrile-water (15:85).

The temperature in the column compartment was $35^{\circ} \mathrm{C}$ and the flow rate of the mobile phase was kept constant at $0.8 \mathrm{ml} / \mathrm{min}$. Under these conditions the retention times of authentic cortisone and cortisol standards were $12.13 \mathrm{~min}$ and $12.84 \mathrm{~min}$, respectively.

The PDA-100 detector response was recorded in UV mode at $239 \mathrm{~nm}$ for cortisone and $243 \mathrm{~nm}$ for cortisol at the appropriate retention times. Cortisone and cortisol amounts were determined according to a calibration curve and final values were corrected for procedural and extraction losses according to yields of internal standard.

Salivary cortisol was determined using the method published by Bičíková et al. (1988). The method consisted of non-extraction solid phase radioimmunoassay using coated tubes with rabbit polyclonal antiserum to cortisol-3-O(carboxymethyloxime) bovine serum albumin conjugate, and homologous $\left[{ }^{125} \mathrm{I}\right]$ tyrosine methylester derivative as a tracer. Frozen saliva was thawed and centrifuged at $3000 \mathrm{rpm}$ for $10 \mathrm{~min}$ to clear off the debris and mucosa residues. The material was then pipetted by automatic analyzer (Stratec, Immunotech, Marseille, France). Intra-assay coefficients of variation (CVs) were $7.4 \%$, and inter-assay CVs were $10.2 \%$ for salivary cortisol.

Unconjugated DHEA was determined by radioimmunoassay kit from Immunotech (Marseille, France) after extraction with dichloromethane. Intra- and inter-assay CVs $7.2 \%$ and CVs $11.9 \%$.

Plasma-ACTH was measured using commercial Immunoradiometric assay (IRMA) kits (Immunotech, France). Minimum detection limit for ACTH was 1.2 pg/mL. Intra- and inter-assay CVs were $9.1 \%$ and $9.6 \%$.

CBG was measured by radioimmunoassay kit (MG 130 61, Immuno-Biological Laboratories, Hamburg, Germany). The analytical parameters corresponded to those given by the manufacturer.

Value of free (unbound) cortisol was calculated according to Coolen's equation (Coolens et al. 1987).

\section{Statistics}

Differences in the basal levels of substances before and after treatment by $\mathrm{COC}$ were tested using Wilcoxon's robust paired test. The effects of $\mathrm{COC}$ and time in ACTH tests were evaluated using ANOVA model consisting of the independent factors of treatment (with COC, without COC), Time (0 min, 20, 30, 40, 60 min) and the subject (each of the examined women) and the Treatment $\times$ Time interaction followed by the least significant difference multiple comparisons. Due to nonGaussian data distribution and heteroscedasticity in some data and residuals, the variables concerned were transformed using power transformation before the ANOVA testing. The non-homogeneities after data transformation were identified using studentized residuals. If the absolute value of the studentized residual was greater than 3 , the experimental point was regarded as outlier and excluded from the analysis. The number of outliers never exceeded $5 \%$ of the total number of experimental points.

\section{Results}

\section{Serum cortisol}

The mean basal concentration of total serum cortisol at baseline period was $454.0 \pm 125.0 \mathrm{nmol} / 1$ (mean $\pm \mathrm{SD}$ ) and it increased to $860.9 \pm 179.7 \mathrm{nmol} / \mathrm{l}$; at COC 

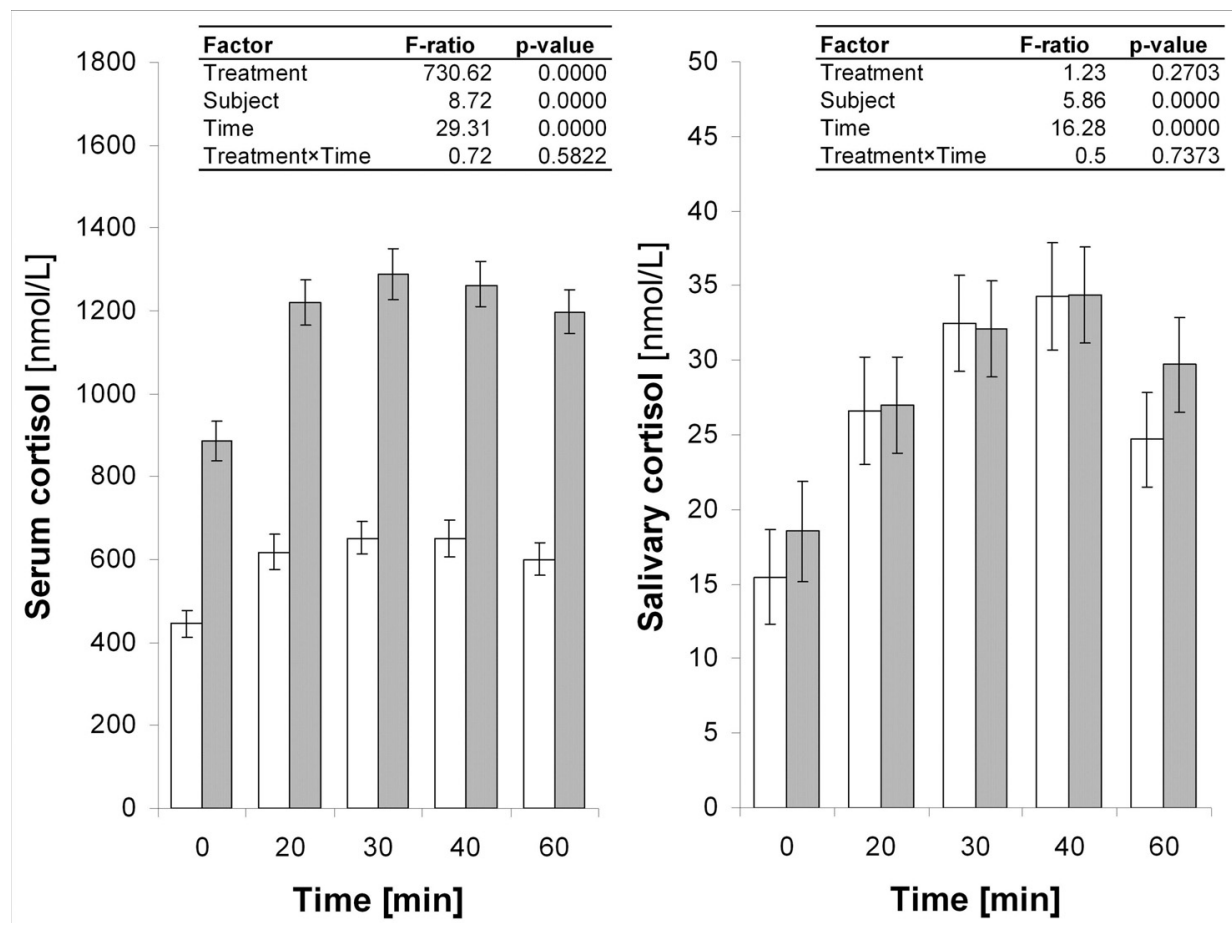

Fig. 1. Serum and salivary levels before and after the injection of $1 \mu \mathrm{g} \mathrm{ACTH}$ in normal women (shaded bars) and after 3 month of using oral contracetion (open bars). The empty and dotted bars with error bars represent retransformed means with their $95 \%$ confidence intervals for the stages with and without treatment with $\mathrm{COC}$, respectively, in individual time points of the ACTH test. The group means the confidence intervals of which do not overlap are significantly different $(p<0.05$, least significant difference multiple comparisons). For details see "Statistical data analysis".

Table 1. Basal levels cortisol and related substances before and after treatment and their differences.

\begin{tabular}{|c|c|c|c|c|c|c|c|c|}
\hline \multirow[t]{2}{*}{ Substance } & \multirow[b]{2}{*}{$\mathrm{n}$} & \multicolumn{2}{|c|}{ Without COC } & \multicolumn{2}{|c|}{ With COC } & \multicolumn{2}{|c|}{$\begin{array}{l}\text { Difference } \\
\text { (with - without) }\end{array}$} & \multirow[t]{2}{*}{$\begin{array}{l}\text { Significance } \\
\text { of the mean } \\
\text { difference* }\end{array}$} \\
\hline & & mean & SD & mean & SD & mean & SD & \\
\hline Transcortin [nmol/l] & 11 & 991.0 & 161.2 & 2331.8 & 428.3 & 1340.7 & 354.9 & $p<0.004$ \\
\hline Free cortisol [nmol/l] & 11 & 22.78 & 14.85 & 19.20 & 6.956 & -3.572 & 13.91 & NS \\
\hline Salivary cortisol [nmol/l] & 11 & 15.48 & 7.655 & 18.99 & 8.913 & 3.516 & 10.85 & NS \\
\hline Total cortisol [nmol/l] & 11 & 454.6 & 131.1 & 860.9 & 188.4 & 406.3 & 159.5 & $p<0.004$ \\
\hline Cortisone [nmol/l] & 11 & 38.84 & 7.679 & 45.15 & 24.23 & 6.309 & 22.84 & NS \\
\hline DHEA [micromol/l] & 11 & 24.6 & 15.7 & 22.6 & 11.7 & 9.1 & 23.8 & NS \\
\hline ACTH [nmol/l] & 11 & 17.20 & 9.540 & 38.24 & 30.88 & 21.03 & 30.66 & $\mathrm{p}<\mathbf{0 . 0 3}$ \\
\hline
\end{tabular}

*Wilcoxon's robust paired

period $(\mathrm{p}<0.0001)$. After $1 \mu \mathrm{g}$ ACTH stimulus, the basal serum $\mathrm{F}$ increased at the $20^{\text {th }}, 30^{\text {th }}, 40^{\text {th }}$ min to $599.9 \pm 68.2 ; 652.3 \pm 60.5 ; 632.3 \pm 67.5 ; 603.7 \pm 52.2 \mathrm{nmol} / 1$ at baseline period, while at $\mathrm{COC}$ period it rised to $1231.4 \pm 232.7, \quad 1374.1 \pm 240.6, \quad 1270.4 \pm 197.6$, $1204.6 \pm 186.5 \mathrm{nmo} / 1$ at the $20^{\text {th }}, 30^{\text {th }}, 40^{\text {th }}, 60^{\text {th }} \mathrm{min}$ $(\mathrm{p}<0.0001)$ (Fig. 1, Table 1).

The basal calculated value of free cortisol in blood was $22.8 \pm 14.9 \mathrm{nmol} / \mathrm{l}$ at baseline period; while at
COC period it decreased to $19.0 \pm 9.6 \mathrm{nmol} / \mathrm{l}$. However, this difference was not statistically significant.

\section{Salivary cortisol}

The mean basal salivary $\mathrm{F}$ was $15.4 \pm 7.3 \mathrm{nmol} / \mathrm{l}$ at baseline period at COC period was $18.9 \pm 8.5 \mathrm{nmol} / \mathrm{l}$; $\mathrm{p}=\mathrm{NS}$. The ACTH-stimulated levels of salivary cortisol were at the $20^{\text {th }} 30^{\text {th }}$ and $40^{\text {th }}$ min with concentration of $25.2 \pm 6.8,32.4 \pm 8.8$ and $32.1 \pm 10.6 \mathrm{nmol} / \mathrm{l}$ at baseline 
period, respectively, and 27.0 $\pm 9.4,32.9 \pm 9.0$ and $34.3 \pm 7.4$ $\mathrm{nmol} / \mathrm{l}$ at COC period; $\mathrm{p}=\mathrm{NS}$. In the $60^{\text {th }} \mathrm{min}$ of $\mathrm{ACTH}$ test, the concentration of salivary cortisol was $24.6 \pm 3.4$ and $29.7 \pm 9.6 \mathrm{nmol} / \mathrm{l}$ at baseline period and COC period respectively; $\mathrm{p}=\mathrm{NS}$.

\section{Other hormones}

The basal plasma concentration of ACTH was $17.2 \pm 9.0 \mathrm{ng} / \mathrm{l}$ at baseline period and increased significantly to $38.2 \pm 29.4 \mathrm{ng} / \mathrm{l}$ at COC period $(\mathrm{p}<0.03)$.

Baseline basal and ACTH-stimulated levels of cortisone in blood did not differ significantly from the data of COC period (basal $38.8 \pm 7.7$, at $20^{\text {th }} \mathrm{min}$. $33.6 \pm 8.1$, at $30^{\text {th }} \mathrm{min} .34 .8 \pm 10.9$, at $40^{\text {th }} \min 37.1 \pm 6.9$, at $60^{\text {th }} \mathrm{min} 38.1 \pm 11.2 \mathrm{nmol} / 1$ in baseline period vs basal $45.2 \pm 24.2$, at $20^{\text {th }} \mathrm{min} 49.1 \pm 30.1$, at $30^{\text {th }} \mathrm{min}$. $47.0 \pm 35.7$, at $40^{\text {th }} \mathrm{min} 46.8 \pm 35.9$, at $60^{\text {th }} \min 47.9 \pm 35.6 \mathrm{nmol} / 1$ in the COC period (NS).

Baseline serum CBG concentration in blood was $991.0 \pm 161.0 \mathrm{nmol} / \mathrm{l}$ and increased to $2332.0 \pm 428.0$ $\mathrm{nmol} / \mathrm{l}$ at COC period $(\mathrm{p}<0.004)$.

The serum concentrations of unconjugated DHEA did not show any significant difference between baseline and COC data. The respective obtained values were $24.6 \pm 15.7 \mu \mathrm{mol} / 1$ and $22.6 \pm 11.7 \mu \mathrm{mol} / 1$ (NS).

\section{Discussion}

Endogenous and synthetic estrogens (COC) cause an increase in $\mathrm{CBG}$ concentration, which results in an elevation of the total cortisol level. Therefore, it is considered appropriate to include free cortisol assessment in the interpretation of the results of the HPA axis examination (Gozansky et al. 2005, Meulenberg et al. 1987).

In our study, we found that the increase in the levels of CBG concentration at COC period. Therefore it is not surprising that basal and stimulated levels of serum cortisol after 3-months administration of COC increased, which is in agreement with other authors (MarcusPerlman et al. 2006, Gozansky et al. 2005). Unlike serum cortisol, the baseline concentration of basal and ACTHstimulated salivary cortisol did not differ from COC period. Our results concerning salivary cortisol are similar to data reported by Marcus-Perlman et al. (2006), although the study groups were different. In that study a group of healthy females and males was compared with other group of hyperestrogenic females using COC and hormone replacement therapy. The cohort of our study was defined more accurately, as the same women were examined before and after treatment with COC, and all of them used only low dose formulation, which is also important.

We found significantly higher levels of ACTH at COC period. Some experimental studies have shown that both basal as well as stimulated ACTH and corticosterone levels are higher in rats during the ovulation period. Studies with humans did not provide such definite conclusions (Kirschbaum et al. 1993) Two studies with humans (Stewart et al. 1993, Genazzani et al. 1975) showed cyclic changes only in non-stimulated ACTH during the menstrual cycle. The Kirschbaum's study only proved changes in salivary cortisol in response to psychosocial stress and ACTH stimulation during menstrual cycle but serum ACTH concentration was unchanged. Jacobs et al. (1989) described, reduced ACTH plasma levels in oral triphasic contraceptive users, which were and significantly lower following the $\mathrm{CRH}$ infusion compared to controls. In Jacobs study, the group of women taking a triphasic oral contraceptive were examined and the results were compared with the control group of women. However, in our study, the same group of women was examined

Increased levels of ACTH may result from the change in the activity of the HPA axis after the administration of COC. However, this is in contrast to unchanged basal salivary cortisol and calculated value of free cortisol after the administration of COC. We did not investigat the ACTH-stimulated calculated value of cortisol. The ACTH-stimulated calculated cortisol did not correlate with salivary cortisol because of not account all of the proteins to which cortisol can potentially bind (Christ-Crain et al. 2007, Ho et al. 2006). Moreover, we did not observe an increased DHEA level as would be expected at higher levels of ACTH. More detailed investigation of the influence of COC administration on the HPA axis activity is highly needed.

Theoretically, the increased levels of ACTH, which we observed, could have resulted from COC induced changes of tissue metabolism of glucocorticoids in periphery. $11 \beta$-hydroxysteroid dehydrogenase type 1 is an enzyme allowing for conversion of cortisone to cortisol. Experimental studies have shown that estrogens reduce the activity of this enzyme (Low et al. 1993, Tomlinson et al. 2004). We did not observe any changes in basal or ACTH- stimulated serum cortisone levels at COC period as compared with baseline data. The changes of glucocorticoid metabolism may be observed only at 
the tissue level without changed serum cortisone. Further investigation of glucocorticoid metabolism at tissue level in COC administration will be challenge.

To conclude, we proved that the assessment of free cortisol is a relevant approach to the evaluation of HPA axis function. We confirmed that salivary cortisol levels do not change after COC administration, and therefore its determination is more favorable for evaluation of adrenal function disorders by low-dose ACTH test, particularly in mild forms of adrenal insufficiency. Assessment of free salivary cortisol is especially valuable in cases with altered CBG concentration either due to either COC administration or some pathological conditions (obesity, catabolic states, renal and liver diseases, etc.).

Since COC administration is a widely used, including in groups of women with increased risk of adrenal gland disturbances, assessment of free salivary cortisol can provide a valuable method for earlier diagnosis of such serious disorders.

\section{Conflict of Interest}

There is no conflict of interest.

\section{Acknowledgements}

We thank the study participants and our excellent research nurses. We further thank Jana Vrbíková, MD, Ph.D. and Kateřina Dvořáková, MD for their excellent advice. We also thank the members of our steroid research group and Martina Vondrová for language assistance. The study was supported by grant NR/9154-3 of the Internal Grant Agency of the Ministry of Health of the Czech Republic (IGA MZCR).

\section{References}

AARDAL E, HOLM AC: Cortisol in saliva- reference range and relation to cortisol in serum. Eur J Clin Chem Clin Biochem 33: 927-932, 1995.

BIČÍKOVÁ M, HAMPL R, PUTZ Z, STÁRKA L: Comparation of isotope variants of direct cortisol immunoassay. Advances in Steroid Analysis 87, S. GOROG (ed.), Akademiai Kiado, Budapest, 1988, pp 101-106.

BJORNTORP P, ROSMOND R: Hypothalamic origin of the metabolic syndrom X. Ann NY Acad Sci 892: $297-$ $307,1999$.

BARKER JM: Type 1 diabetes-associated autoimmunity: natural history, genetic associations, and screening. $J$ Clin Endocrinol Metab 91: 1210-1217, 2006.

BETTERLE C, DAL PRA CH, MANTERO F, ZANCHETTA R: Autoimmune adrenal insufficiency and autoimmune polyendocrine syndromes: autoantibodies, autoantigens, and their applicability in diagnosis and disease prediction. Endocr Rev 23: 327-364, 2002.

CONTRERAS LN, ARREGGER AL, PERSI GG, GONZALEZ NS, CARDOSO EM: A new less-invasive and more informative low-dose ACTH test: salivary steroid in response to intramuscular corticotrophin. Clin Endocrinol 61: 675-682, 2004.

CHRIST-CRAIN M, JUTLA S, WIDMER I, COUPPIS O, KÖNIG C, PARGGER H, PUDER J, EDWARDS R, MÜLLER B, GROSSMAN AB: Measurement of serum free cortisol shows discordant responsivity to stress and dynamic evaluation. J Clin Endocrinol Metab 92: 1729-1735, 2007.

COOLENS JL, VAN BAELEN H, HEYNS W: Clinical use of unbound plasma cortisol as calculated from total cortisol and corticosteroid-binding globulin. J Steroid Biochem 26: 197-202, 1987.

DICKSTEIN G, SPIGEL D, ARAD E, SHECHNER C: Adrenocorticotropin stimulation test: effects of basal cortisol level, time of day, and suggested new sensitive low dose test. J Clin Endocrinol Metab 72: 773-778, 1991.

GENAZZANI AR, LEMARCHAND-BERAUD T, AUBERT ML, FELBER JP: Pattern of plasma ACTH, hGH, and cortisol during menstrual cycle. J Clin Endocrinol Metab 41: 431-437, 1975.

GOZANSKY WS, LYNN JS, LAUDENSLAGER ML, KOHRT WM: Salivary cortisol determined by enzyme immunoassay is preferable to serum cortisol for assessment of dynamic hypothalamic-pituitary-adrenal axis activity. Clin Endocrinol 63: 336-341, 2005.

HO JT, AL-MUSALHI H., CHAPMAN MJ, QUACH T, THOMAS PD, BAGLEY CJ, LEWIS JG, TORPY DJ: Septic shoc and sepsis: a comparison of total and free plasma cortisol levels. J Clin Endocrinol Metab 91: 105-114, 2006. 
JACOBS AJ, ODOM MJ, WORD RA, CARR BR: Effect of oral contraceptives on adrenocorticotropin and growth hormone secretion following CRH and GHRH administration. Contraception 40: 691-699, 1989.

KIRSCHBAUM C, KUDIELKA BM, GAAB J, SCHOMMER NC, HELLHAMMER DH: Impact of Gender, Menstrual cycle phase, and oral contraceptives on the activity of the hypothalamus-pituitary-adrenal axis. Psychosom Med 61: 154-162, 1999.

LOW SC, ASSAAD SN, RAJAN V, CHAPMAN KE, EDWARDS CR, SECKL JR: Regulation of 11 betahydroxysteroid dehydrogenase by sex steroids in vivo: further evidence for the existence of a second dehydrogenase in rat kidney. $J$ Endocrinol 139: 27-35, 1993.

MARCUS-PERLMAN Z, TORDJMAN K, GREENMAN Y, LIMOR R, SHENKERMAN G, OSHER E, STERN N: Low-dose ACTH $(1 \mu \mathrm{g})$ test: a potential alternative to the classical blood test. Clin Endocrinol (Oxf) 64: 215218, 2006.

MEULENBERG PM, ROSS HA, SWINKELS LM, BENRAAD TJ: The effect of oral contraceptives on plasma-free and salivary cortisol and cortisone. Clin Chim Acta 165: 379-385, 1987.

REYNOLDS RM, WALKER BR, SYDDALL HE, WHORWOOD CB, WOOD PJ, PHILLIPS DJ: Elevated plasma cortisol in glucose- intolerant men: differences in responses to glucose and habituation to venepunction. $J$ Clin Endocrinol 86: 1149-1153, 2001.

ŠIMŮNKOVÁ K, HAMPL R, HILL M, DOUCHA J, STÁRKA L, VONDRA K: Salivary cortisol in low dose (1 $\mu \mathrm{g})$ ACTH test in healthy women: comparison with serum cortisol. Physiol Res 56: 449-453, 2007.

STEWART PM, PENN R, HOLDER R, PARTON A, RATCLIFFE JG, LONDON DR: The hypothalamo-pituitaryadrenal axis across the normal menstrual cycle and in polycystic ovary syndrome. Clin Endocrinol 38: 387391, 1993.

TOMLINSON JW, WALKER EA, BUJALSKA IJ, DRAPER N, LAVERY GG, COOPER MS, HEWISON M, STEWART PM: 11ß-hydroxysteroid dehydrogenase type 1: A tissue-specific regulator of glucocorticoid response. Endocr Rev 25: 831-866, 2004.

VICENNATI V, PASQUALI R: Abnormalities of the hypothalamic-pituitary-adrenal axis in nondepressed woman with abdomnal obesity and relations with insuline resistance: evidence for a central and a peripheral alteration. J Clin Endocrinol Metab 85: 4093-4098, 2000. 